\title{
Afinal, o que é "cine imperfecto"? Uma análise das ideias de García Espinosa
}

Fabián Núñez ${ }^{1}$

1. Professor adjunto do departamento de cinema e vídeo da Universidade Federal Fluminense (UFF). A sua formação acadêmica foi inteiramente realizada nessa instituição: Doutor em Comunicação, em 2009; Mestrado em Comunicação, Imagem e Informação, em 2003; e Bacharel em Comunicação Social (habilitação em cinema), em 2000. Suas areas de interesse são: história do cinema, cinema latino-americano, cinema brasileiro, crítica cinematográfica e preservação audiovisual. E-mail: fabian_nunez@id.uff.br 


\section{Resumo}

O presente trabalho busca esmiuçar as ideias do cineasta e ensaísta cubano Julio García Espinosa. Desse modo, propomos ler a sua obra teórica para além de seu célebre manifesto "Por un cine imperfecto". Cremos que uma análise de seus textos imediatamente posteriores ao manifesto - pouco estudados - nos auxilia em uma maior compreensão de suas ideias, inclusive do seu famoso conceito "cine imperfecto". Assim, nos propomos a esclarecer esse termo, fugindo da leitura tradicional do artigo "Por un cine imperfecto", que o isola dos textos posteriores do autor.

\section{Palavras-chave}

cinema latino-americano, cinema cubano, teorias de libertação nacional, estética

\section{Abstract}

The present study attempts to scrutinize the ideas of the Cuban filmmaker and essayist Julio García Espinosa. Thereby, we propose to read his theoretical work beyond his famous Porun cine imperfecto manifesto. We believe that an analysis of his little-studied papers written immediately after the manifesto, helps us to a greater understanding of his ideas, including his famous concept of "cine imperfecto". Thus, we propose to clarify this term, avoiding the traditional reading of the article Porun cine imperfecto, which isolates it from the author's later writings.

\section{Keywords}

latin american cinema, Cuban cinema, theories of National Liberation, aesthetics 
temáticas

livres

\section{Introdução}

Em dezembro de 1969, Julio García Espinosa escreve o texto "Por un cine imper fecto", ${ }^{2}$ que irá conhecer uma for te repercussão no âmbito cinematográfico latino-americano. O termo "cine imperfecto", talvez por sua ambiguidade, causou furor, sobretudo por uma leitura equivocada da expressão, que García Espinosa buscou imediatamente esclarecer. ${ }^{3}$ Inicialmente, ressaltamos que o famoso texto está preocupado em analisar o cinema cubano. Porém, como se volta a especulações abstratas, acaba por possuir um aspecto bem mais amplo. Concordamos com Avellar (1995: 174-218), que afirma tratar-se de um manifesto atípico, por possuir mais inter rogações do que respostas (apesar de que há muitas perguntas retóricas). É um artigo cuja leitura pode ser um tanto confusa, mas que expressa, por sua própria escrita, um esforço em buscar um novo conceito que dê conta da situação cinematográfica latino-americana da época. García Espinosa, em suas entrevistas e textos, do período (virada da década de 1960/70) e depois, ${ }^{4}$ argumenta a necessidade de uma reflexão teórica sobre a produção

2. "[...] escrito em dezembro de 1969, foi primeiro em cópia mimeografada; em seguida divulgado durante a Sexta Mostra Internazionale del Nuovo Cinema de Pesaro, Itália, em junho de 1970; publicado em Hablemos de Cine no 55/56, Lima, setembro/dezembro de 1970; em Cine del Tercer Mundo, $\mathrm{n}^{\circ}$ 2, Montevidéu, novembro de 1970; em Cine Cubano, n 66/67, Havana, janeiro/março de 1971 e em Comunicación y Cultura n ${ }^{\circ}$ 1, Santiago do Chile, julho de 1973, entre outros periódicos" (AVELLAR, 1995, p. 209). O ensaio também foi publicado em coletâneas de García Espinosa (1970: 11-32; 1996: 1328) e está disponível em: http://www.cinelatinoamericano.org/biblioteca/assets/docs/documento/437. pdf. Acesso em: 14 de novembro de 2011.

3. Ver principalmente a sua carta à revista chilena Primer Plano, na qual responde a uma forte crítica ao seu artigo: "Julio García Espinosa responde". Primer Plano, Valparaíso, v. I, nº 4, p. 36-42, Primavera 1972. Transcrito em Cine Cubano, no 81-82-83, Havana, 1973. p. 133-139. Reproduzido em García Espinosa (1970: 39-53), sob o título "Desarrollar una nueva cultura sobre el cadáver de los últimos burgueses". Disponível em: http://www.cinelatinoamericano.org/biblioteca/assets/docs/documento/440.pdf. Acesso em: 14 de novembro de 2011.

4. Sobretudo em "Por un cine imperfecto: veinticinco años después", de 1994 (GARCÍA ESPINOSA, 1996: 121-128). 
do jovem cinema cubano Pós-Revolução. Tal necessidade partiu de uma análise de sua própria obra fílmica, ao afirmar que seus dois primeiros longas - Cuba baila (1960) e El joven rebelde (1961) - são pouco “pessoais". Não que os negue, mas refere-se a eles como obras artisticamente imaturas e historicamente datadas, como a expressão de uma primeira fase do cinema revolucionário, diferenciando-se totalmente de seu terceiro longa, Aventuras de Juan Quin Quín (1967). Assim, o cineasta descreve o modelo estético que guiou a produção dos primeiros filmes do Instituto Cubano del Arte e Industria Cinematográficos (ICAIC): o Neorrealismo italiano. Aliás, ressaltamos que García Espinosa e Tomás Gutiérrez Alea foram alunos, no início dos anos 1950, do Centro Sperimentale di Cinematografia, em Roma. A permanência de Cesare Zavattini em Cuba, por ocasião da realização de El joven rebelde, expressa o diálogo entre os italianos e os cubanos. É curioso refletir que o movimento italiano já estava em declínio nesse período, sobretudo se levarmos em consideração as inovações estéticas dos chamados "cinemas novos". Portanto, no final dos anos 1960, os cineastas cubanos se voltam para uma produção cinematográfica mais próxima à estética dessa renovação. É o período de filmes que são considerados clássicos do Nuevo Cine Latinoamericano (NCL): o citado Aventuras de Juan Quin Quín, Memorias del subdesarrollo (1968), de Gutiérrez Alea, Lucía (1968), de Humberto Solás e La primera carga al machete (1969), de Manuel Octavio Gómez, estes dois últimos com a participação de García Espinosa no roteiro. Ou seja, o modelo neorrealista é rompido e, segundo García Espinosa, ou melhor dito, segundo o próprio discurso oficial do ICAIC, é nesse momento que o cinema cubano, desde as suas origens pré-revolucionárias, alcança a sua maturidade.

Portanto, o texto "Por un cine imperfecto" está inserido em um período de reflexão teórico-histórica do cinema cubano, vislumbrando os rumos dessa cinematografia. Assim, o aspecto chave para guiar a leitura do texto é considerar que o autor está falando de um país subdesenvolvido, mas que realizou a sua revolução. Portanto, a sua reflexão se volta aos dilemas de uma cinematografia 
ano I número I

temáticas

livres

singular, já que é oriunda de um país periférico, mas visa ultrapassar o capitalismo. Assim, o autor analisa o papel da arte em uma sociedade industrial e sobretudo de uma arte industrial por definição: o cinema. Porém, como se trata de um país subdesenvolvido, os dilemas dessa manifestação artístico-cultural e industrial adquirem outros aspectos. Por outro lado, é necessário ressaltar que se trata de uma cinematografia estatal, ou seja, cujos meios de produção e difusão são regidos por uma planificação do Estado.

2. "Por un cine imperfecto": reflexões revolucionárias do subdesenvolvimento

Frisamos que o objeto de análise do célebre manifesto de García Espinosa é a cinematografia cubana. Ou seja, trata-se de um cinema extremamente singular, por ser estatal - e no seio de um país subdesenvolvido, o que iremos, posteriormente, abordar. Esse "localismo" do texto - praticamente ignorado em suas análises - não o impede de abordar temas mais amplos e, por conseguinte, servir de rastro teórico para a(s) cinematografia(s) do subcontinente latino-americano, em geral.

Por se tratar de uma produção em um país socialista, García Espinosa se questiona por que alguns cubanos são cineastas e outros não. Ou seja, por que somente um corpo de especialistas detém os meios de produção audiovisual. Tal questionamento leva o autor a declarar que a atividade artística é um aspecto inerente à condição humana, porém apenas alguns homens possuem o privilégio de exercê-la. Dito de outro modo, a arte é uma atividade "desinteressada", segundo os termos do autor, pois não possui um fim exato. A obra de arte se define por sua inutilidade, não em um sentido pejorativo, pelo contrário, mas como uma atividade da inteligência humana que não está destinada a uma finalidade específica. Nesse ponto, o autor contrapõe arte a ciência, sendo ambas atividades humanas, mas que se diferenciam por seu prestígio e 
funcionalidade. ${ }^{5} \mathrm{O}$ relevante é sublinhar que somente uma sociedade dividida em classes pode gerar a estranha figura do artista profissional, do ser humano que faz de uma atividade "desinteressada" o seu fim.

Por que tal questão se torna evidente nos dias de hoje? - interroga-se o autor. García Espinosa vê na arte moderna um sintoma dessa sociedade cindida, seja por sua crise de público ou (o que talvez seja o mais relevante, mas não tão explícito no texto) pelo questionamento da função do artista e da obra de arte. Ao abordar esse assunto, podemos identificar que o autor discute, de modo pouco diferenciado, dois pontos. Um deles é a figura do artista e da arte na sociedade industrial, ao questionar o que entendemos ser a arte no sentido tradicional do termo (isso que, em textos posteriores, o autor denominará de "artes pré-industriais"). O outro ponto são as contradições da sociedade industrial que, segundo o otimismo do autor, desaguará em sua superação, ou seja, no advento da sociedade socialista e, por conseguinte, no fim da divisão de classes.

Segundo o autor, três fatores confirmam o fim da sociedade de classes: 1) o desenvolvimento da ciência (e, nesse item, García Espinosa não faz distinção entre as ciências humanas e a tecnologia, oriunda da aplicação das ciências exatas); 2) a presença social das massas (ou seja, a conscientização do proletariado); e 3) a potencialidade revolucionária das massas (ressaltamos que 1968 ainda é uma lembrança recente). Como o autor concilia esses três fatores? O desenvolvimento da ciência e da tecnologia e das teorias e práticas sociais tornou possível uma maior participação política das camadas populares na sociedade contemporânea. Isso significa que, graças ao advento dos meios de comunicação de massa, do aumento das horas de lazer e da conscientização política, houve um aumento do público consumidor de arte. Ou seja, o público

\footnotetext{
5. García Espinosa (1996: 47-74) não faz uma distinção clara entre ciência e tecnologia, mas não iremos discutir isso. Assinalamos que, posteriormente, ele usará a expressão "desenvolvimento" ou "revolução científico-técnica".
} 
ano I número |

temáticas

livres

aumentou. Essa é a primeira fase da “deselitização" da arte: uma maior difusão educacional e cultural por conta das mídias. ${ }^{6}$ Porém, o relevante para García Espinosa não é a perspectiva, a longo (e utópico) prazo, de que todos tenham o mesmo gosto, ditado pelos parâmetros da arte erudita, mas que todos possam ser criadores de cultura artística. Eis o cerne do texto: o fim da divisão entre criadores e consumidores de arte. O ideal seria que todos pudessem ser artistas. Dito de outro modo, já que a atividade ar tística é algo inerente à condição humana, o correto seria que todos pudessem se manifestar artisticamente. Quando o autor questiona a criação de escolas de cinema em Cuba, está chamando a atenção para a recriação de um mundo onde há cineastas e espectadores. Por outro lado, se a figura do cineasta é uma "aberração", a de um espectador profissional, ou seja, o crítico, é o seu correlato “aberrante”. Em um mundo sem uma divisão do trabalho em classes não haveria cineastas nem críticos. Veremos, ao longo deste trabalho, como García Espinosa matiza a figura do crítico no desenrolar teórico de seus textos.

Segundo o autor, essa arte já existe: é a arte popular, que não deve ser confundida com arte de massas. Na arte popular não há divisão entre criadores e consumidores. Assim, o ideal não é difundir a "cultura erudita", classista por definição, mas reconhecer que todos, independente de classe, são capazes de produção cultural. Ou seja, não existe "a" cultura, mas várias culturas. Por outro lado, para o autor, com a redução da equipe de filmagem, graças ao desenvolvimento tecnológico, é possível prever que em breve todos serão

6. Em suma, houve um aumento da camada da população com acesso às manifestações artísticas e culturais. Esse raciocínio, o da "democratização da cultura", é a base argumentativa do primeiro pronunciamento oficial do governo revolucionário em relação à política cultural em Cuba, em junho de 1961, segundo o célebre discurso de Fidel Castro, intitulado "Palabras a los intelectuales", conhecido por sua consigna: "Dentro de la Revolución, todo; contra la Revolución, nada." Para maiores informações, ver a abordagem sobre o "Caso P.M." (VILLAÇA, 2010: 51-59). Ver também o discurso de Fidel Castro, no sítio do Ministério da Cultura da República de Cuba. Disponível em: http://www.min.cult.cu/loader. php?sec=historia\&cont=palabrasalosintelectuales. Acesso em: 14 de novembro de 2011. 
capazes de produção fílmica, o que significa o fim da própria figura do cineasta, ou seja, de um especialista dos meios de produção audiovisual. ${ }^{7}$

Para o autor, esse deve ser o objetivo do cinema latino-americano. E, graças ao seu otimismo terceiro-mundista, o potencial revolucionário das camadas populares da América Latina é algo óbvio. Como a revolução visa terminar com a divisão de classes e, por conseguinte, estabelecer uma prática cultural na qual não há distinção entre criadores e consumidores, a prática revolucionária não é apenas um ato político, mas também cultural. Se o artista é consciente do que é a arte e, por tal motivo, luta para terminar com a figura do artista profissional, ele deve criar uma arte que possui uma finalidade bem clara: se unir à prática revolucionária. Por definição, tal arte é “interessada”, pois não é uma atividade sem finalidade específica, já que é uma arte militante. Assim, o autor prega um cinema que seja “interessado" e, portanto, imperfeito. Um cinema "desinteressado" somente será possível quando seja o próprio povo quem o faça. Sublinhamos que um cinema militante é "imperfeito" porque ainda é realizado por um corpo de especialistas, os cineastas, para um novo destinatário: as massas revolucionárias do Terceiro Mundo. E nesse ponto há uma singularidade em relação à teoria cinematográfica soviética, pois não estamos trabalhando apenas com o tradicional conceito marxista de "classe", mas também com o conceito de "povo", caro às Teorias de Libertação Nacional. Assim, trata-se de uma arte militante, não no sentido tradicional, mas uma arte que visa se unir à luta de um povo. Esse cinema já existe. Para García Espinosa, os "cinemas novos" da América Latina são esse "cinema imperfeito". Por outro lado, o público para esse cinema também já existe. São “os que lutam”, as massas revolucionárias. Então, o Nuevo Cine Latinoamericano não necessita criar um público; pelo contrário, há mais público do que cineastas suficientes.

\footnotetext{
7. Veremos, mais adiante, que um dos sentidos do termo "cine imperfecto" é a afirmação do uso das condições técnicas que os cineastas do Terceiro Mundo possuem, mesmo que elas sejam as mais precárias.
} 
ano I número |

temáticas

livres

Portanto, cada cinematografia será distinta, pois depende da capacidade tecnológica e artística de seus cineastas, do grau político de seu público e das particularidades culturais de cada povo. Assim, não existem regras estéticas a priori para esse cinema. Pode ser documentário ou ficção ou mesmo ambos; pode ser um gênero ou vários; pode ser cômico ou não. Podemos constatar que desde o célebre texto de 1969, García Espinosa se defronta com um certo tipo de cinema que, por falta de termo melhor, chamaremos de "cinema de espetáculo". Qual é o papel da diversão no processo revolucionário? Como lidar com a herança, em termos de gênero e de linguagem cinematográfica, do cinema comercial? Tais questionamentos afloram com mais força em sua carta à revista chilena, escrita em outubro de 1972, e em outros textos posteriores. No entanto, já podemos reconhecer o embaraço com que o cubano se defronta ao tentar conciliar militância com diversão, para fugir do espetáculo.

Em suma, o "cine imperfecto" não é um cinema militante no sentido tradicional do termo, ou seja, por sua temática, mas também por seu modo de produção e difusão. Em relação a esse tópico, o autor comenta o papel da qualidade e da técnica em tal cinema, o que suscitou a má interpretação do conceito "cine imperfecto". Não se trata de um culto ao miserabilismo ou uma apologia ao cinema malfeito. A questão se divide em duas. Uma é romper com a ideologia de que cinema "bem-feito" necessariamente deve ser realizado conforme os moldes do cinema industrial hegemônico. Podemos fazer filmes, mesmo que seja em condições precárias. Óbvio que García Espinosa não contesta o desenvolvimento tecnológico (pelo contrário, conforme o pensamento marxista, as forças produtivas sempre avançam em direção à Revolução), mas os povos do Terceiro Mundo devem utilizar os meios à sua disposição, o que prolonga uma mentalidade herdada do Neorrealismo (ou seja, a crítica ao studio system) e, por conseguinte, desemboca no segundo aspecto da questão, i. e., na criação de um outro conceito de "qualidade estética", seja pelas condições de produção desses filmes ou pelas condições de recepção dos mesmos. Dito de outro 
modo, se o "cinema imperfeito" visa participar da prática revolucionária do povo e se não há regras estéticas definidas, o que interessa ao cineasta é se comunicar com tal público, ainda que seja fora dos tradicionais parâmetros de criação e difusão cinematográfica. Ou seja, o problema é saber qual é a melhor forma de se dirigir a esse público, que não foi "educado" segundo os cânones do "bom gosto" da arte erudita; como fazer um cinema para esse público carente de cinema. O artista, então, não deve mais ver na realização de sua obra a expressão de uma satisfação pessoal. A sua atividade está subordinada - já que é "interessada" (busca um fim específico) - a uma atividade maior: a prática revolucionária. Em suma, o cineasta, mais do que artista, é, antes de mais nada, um homem que luta. García Espinosa afirma que há vários caminhos para o cinema militante, mas o que todos buscam é o diálogo com o público. Assim, o "cine imperfecto" pode ser tanto um cinema que dialoga com a cultura popular (como o cinema cubano e a última fase do Cinema Novo brasileiro), quanto um cinema clandestino, fora dos tradicionais meios de produção, distribuição e exibição (como o do argentino Grupo Cine Liberación e o do boliviano Grupo Ukamau).

\section{Socialismo e industrialismo versus imperialismo e comercialismo}

“Por un cine imperfecto”, segundo o próprio autor, é um texto que possui um complemento, escrito em 1971, intitulado "En busca del cine perdido". ${ }^{8}$ Nesse artigo, García Espinosa afirma que não há distinção entre o cinema comercial e o cinema de autor, o que muito se aproxima da "teoria dos Três Cinemas" do Grupo Cine Liberación. ${ }^{9}$ Mais uma vez, o cubano retorna à questão da relação

8. Publicado nas revistas Cine Cubano no 69-70, Havana, 1971, p. 24-27; Cine al día no 14, Caracas, novembro de 1971, p. 24-25. Transcritas em García Espinosa (1970: 33-38; 1996: 29-33). Disponível em: http://www.cinelatinoamericano.org/biblioteca/assets/docs/documento/439.pdf. Acesso em: 14 de novembro de 2011.

9. SOLANAS, F; GETINO, O. "Hacia un tercer cine: apuntes y experiencias para el desarrollo de un cine de liberación en el Tercer Mundo" [de outubro de 1969]. In: Cine, cultura y descolonización. Buenos Aires: Siglo XXI, 1973, p. 55-91; também publicado em vários periódicos na época. Disponível 
ano I número |

temáticas

livres

cineasta-espectador e à necessidade de superar essa divisão. Assim como na reflexão do conceito de "Tercer Cine" pelo Grupo Cine Liberación, García Espinosa põe em questão tudo o que entendemos por cinema: não apenas as regras estéticas da construção da narrativa fílmica, mas, nos termos do autor, "a instância cultural" que sustenta o fenômeno cinematográfico. Esse é o primeiro ponto de onde o cineasta deve partir, já que um "novo cinema" não parte do zero, mas do que já existe. Portanto, o espectador comum já está acostumado a uma concepção de cinema, e é por essa concepção que o cineasta deve começar a dialogar com ele. Inclusive por um cinema de gênero, o que o cineasta cubano fez com o seu filme Aventuras de Juan Quin Quín. García Espinosa está em busca de um cinema popular e, portanto, deve construir relações com um cinema de gênero e outras manifestações culturais que estão enraizadas no gosto popular, e não no gosto erudito.

Esse é o enjeu de sua carta à revista chilena Primer Plano. Podemos afirmar que, segundo García Espinosa, o objetivo do ICAIC é criar um cinema popular e militante, simultaneamente. Melhor dito, militante por ser popular e, por isso, para usarmos o jargão do autor, um cinema que, por definição, é antiimperialista. O "cine imperfecto" é um cinema anti-imperialista, pois é militante por ser popular e não populista, ${ }^{10}$ como o cinema hegemônico. Existem vários usos para o cinema e o meio pelo qual o filme é difundido repercute na sua recepção por parte do público. O problema das salas de cinema convencionais se deve ao fato de que o público que as frequenta foi formado por um certo tipo de cinema que é exibido nesses espaços. Ou seja, o público "naturaliza” as estruturas narrativas de tais filmes, o que deve ser revertido em nome de uma "nova cultura" que irá desembocar na sociedade socialista:

em: http://www.cinelatinoamericano.cult.cu/biblioteca/assets/docs/documento/489.pdf. Acesso em: 14 de novembro de 2011.

10. Termo-chave que guia a sua reflexão no artigo "Los cuatro medios de comunicación son tres: cine y televisión”, publicado em 1976 (Cf. GARCÍA ESPINOSA, 1996: 47-74). Disponível em: http://www. analitica.com/bitblioteca/garcia_espinosa/cuatro_medios.asp. Acesso em: 14 de novembro de 2011. 
É necessário ter em conta que a sala de cinema habitual é um meio que, por suas características e tradição, condiciona, por enquanto, a ver um determinado tipo de cinema. Temos que fazer os filmes tendo em conta os seus canais de exibição. O desafio que temos adiante é como fazer um cinema para as salas habituais. É necessário estar conscientes de que o cinema que segue basicamente influenciando é o das salas habituais. (...) A operação que faz um filme em uma sala habitual é a de converter pessoas, que são diferentes na realidade, nessa coisa amorfa e homogênea que se chama público. No vestíbulo das salas de cinema, as pessoas deixam as suas diferenças de classe, suas lutas cotidianas, para se converter em público. O prazer que, em geral, nos proporciona um filme é o de nos criar uma pausa na luta de classes. Nós devemos mostrar a luta de classes e revelar a heterogeneidade do público. Esses objetivos os perseguiram sempre todos os cineastas de esquerda (...) Quase sempre quando refletimos a luta de classes se escamoteia o prazer e quando oferecemos prazer se neutraliza a luta de classes. É urgente resolver essa situação (GARCÍA ESPINOSA, 1970: 50-52, tradução nossa).

García Espinosa, conforme as reflexões cinematográficas de seu tempo, questiona um cinema de espetáculo. Assim, os seus textos ao longo dos anos 1970 se caracterizam por questionar a relação entre realidade e ficção e pensar sobre o que é uma narrativa, não apenas no cinema, mas na literatura, no teatro, no rádio e na televisão. ${ }^{11}$ Ao voltar seus olhos para as mídias audiovisuais (cinema e televisão), García Espinosa frisa os dois aspectos que as constituem: o artístico e o industrial. Frutos do desenvolvimento científico-técnico, tais mídias revolucionam todo o modo do homem de se relacionar com o mundo. Como um mar xista coerente, o ensaísta cubano não é contra o desenvolvimento tecnológico, pelo contrário, tal aspecto indica uma transformação na sociedade, que será plenamente utilizada com o advento do socialismo e de uma autêntica manifestação artística, de caráter coletivo e industrial.

11. Esse debate em torno dos gêneros cinematográficos é o centro teórico do cinema cubano dos anos 1970. Podemos destacar os longas ficcionais El hombre de Maisinicú (1973), de Manuel Pérez, filme em estilo de espionagem, e El brigadista (1977), de Octavio Cortázar, em estilo de aventura, ambos recordes de bilheteria em Cuba na década, com quase dois milhões de espectadores. Frisamos que esse debate em torno da relação da produção fílmica nacional com o público se prolonga na década seguinte, nos anos 1980, dando, por conseguinte, grande importância à comédia, gênero até então pouco visitado na cinematografia cubana revolucionária. 
ano I número |

temáticas

livres
Em "Por un cine imperfecto: veinticinco años después" (GARCÍA ESPINOSA, 1996: 121-128), de 1994, o autor traça uma análise das teorias latino-americanas de cinema e, no seu caso particular, da herança neorrealista no cinema cubano. Ao tomarmos esse texto, cremos que podemos buscar pistas para entender, afinal, o que é o "cine imperfecto" e como o artigo de 1969 se inclui em sua obra teórica. As suas reflexões sobre ficção e realidade, nos textos dos anos 1970 e, a partir delas, sobre como buscar um cinema popular, com uma narrativa ao gosto popular, graças à relação cineasta-espectador dentro de uma arte industrial como o cinema, remetem às teorias neorrealistas. Discutir o papel do cinema na sociedade e como se constrói uma narrativa que seja autêntica em relação à realidade são aspectos presentes no debate teórico neorrealista. Por outro lado, há um aspecto singular, ao refletir o que é a arte na sociedade industrial e os dilemas de uma cinematografia periférica, i.e, que não possui uma indústria cinematográfica.

Para tentar desbastar esses problemas, García Espinosa se questiona o que são as mídias (imprensa, rádio, cinema e televisão) e o impacto destas na sociedade (cubana e mundial). Uma pista é a distinção do autor entre "comunicação" e "expressão". As "artes pré-industriais" são o fruto de uma minoria em uma sociedade dividida em classes. Com o advento da sociedade industrial, as massas vão adquirindo um peso maior, até pelo fato do aumento do tempo livre conquistado pelo proletariado. O que torna possível o surgimento de um outro fenômeno: a sociedade de massa. Desse modo, a atividade artística, que, como vimos, é inerente a todos os seres humanos, se choca com uma realidade inédita, o que significa que as condições de produção e recepção dessas artes não são mais as mesmas. Assim, de um modo implícito, o autor define como “expressão" algo típico de uma atividade artística minoritária, i.e., "préindustrial", manifesta, da melhor forma, pela ideologia romântica do "gênio". Por outro lado, "comunicação" se define pela interação igualitária entre, no mínimo, duas pessoas. Assim, de um modo bem simples (e talvez um tanto 
simplório), as mídias industriais, até então, foram utilizadas como canais de difusão da expressão de um corpo de especialistas (os artistas profissionais), e não como canais de comunicação, por não ocorrer a interação que caracteriza um ato humano como uma atividade comunicativa. É um equívoco, pois, referirse às mídias como "meios de comunicação de massa".

Por outro lado, as mídias não são nocivas em si. É por esse motivo que o autor chega a afirmar que as mídias contêm em si muitos meios de comunicação. ${ }^{12}$ Os aspectos negativos de tais mídias se devem à mentalidade, à ideologia "préindustrial" ainda vigente na nossa sociedade. A forte presença do romance oitocentista na televisão, melhor dito, nas telenovelas é um dos pontos mais lúcidos de García Espinosa. Aliás, as suas reflexões sobre a televisão nos parecem muito importantes se levarmos em conta que poucos são os cineastas brasileiros da época que se preocuparam em pensar a relação cinema e televisão e, mais, as singularidades do meio televisivo. ${ }^{13}$ Se "comunicação", por definição, é interação, o termo "linguagem" deve ser repensado. As suas elucubrações sobre a "linguagem escrita" e "oral" são particularmente problemáticas. Melhor dito, são extremamente clássicas, com raízes na filosofia aristotélica. ${ }^{14} \mathrm{O}$ que nos importa é frisar que, para o cineasta cubano, a "linguagem audiovisual" é algo muito recente, ainda em formação, o que explica a sua maior preocupação pelo cinema e pela televisão. Por quê? Porque ambos são filhos da sociedade industrial, ou seja, são “artes industriais". Aliás, como bem sublinha o cubano,

12. "Os meios, insistimos, não são somente um meio para uma maior difusão do conhecimento. Na realidade, os meios não são meios de comunicação, são, sobretudo, a possibilidade de uma nova expressão e percepção da realidade. Os novos meios chamados de comunicação (principalmente, televisão e cinema) contêm em si mesmos muitos meios de comunicação." Transcrito do artigo "Intelectuales y artistas del mundo entero ¡Desuníos!”, publicado em 1973 e transcrito em García Espinosa (1996: 43).

13. Agradecemos ao pesquisador Luís Alberto Rocha Melo, professor da Universidade Federal de Juiz de Fora (UFJF), que nos chamou a atenção para essa marcante diferença.

14. A discussão sobre a linguagem, empreendida por García Espinosa, é profundamente "clássica", o que demonstra que o estruturalismo e a filosofia de Heidegger estão escancaradamente ausentes de seus ensaios teóricos. 
ano I número I

temáticas

livres

a televisão ainda possui problemas no reconhecimento de seu caráter artístico, pois ainda estamos nos referindo a um conceito "pré-industrial" de arte. Todo o esforço de García Espinosa é chamar a atenção para esse fato e, por conseguinte, repensar o que chamamos de arte, pois o desenvolvimento da sociedade industrial culminará na sociedade socialista. Em outros termos, apesar de o cubano nunca ser explícito sobre tal ponto, trata-se de fundamentar um conceito socialista de arte (como sinônimo de "arte popular").

Um dos aspectos positivos do cinema e, sobretudo, da televisão é a "dessacralização" do humano, i.e., da arte no sentido tradicional. Por tal motivo, as "aberrantes" figuras do artista profissional e do crítico devem ser reavaliadas. Em relação ao artigo de 1969, um de 1976 - “Los cuatro medios de comunicación son tres: cine y televisión” (GARCÍA ESPINOSA, 1996: 47-74) - busca "salvar" o papel do crítico, mas para além da função de mero "mediador" entre a obra e o público. Contudo, em última instância, a televisão significa tanto o fim do artista como do crítico, no sentido tradicional do termo. Tais figuras ainda possuem alguma função, mas o ideal é a proletarização de ambos, o que significa a comunhão (e, por conseguinte, comunicação) entre especialistas (artistas e críticos) e o público em geral. As mídias devem abrir o caminho para uma "nova cultura" e destruir sistematicamente o aspecto individualista das "artes pré-industriais". Para isso, é necessário adquirir uma visão global das mídias.

Assim, a consciência da televisão como um complexo quadro de programação, e não uma mera soma de vários programas isolados, repercute na teoria cinematográfica, em como pensar uma cinematografia nacional. Nesse ponto, devemos ressaltar o caráter estatal do cinema cubano. Aliás, é relevante sublinhar que a partir dos anos 1970, García Espinosa assume diversos cargos no alto escalão do setor cultural cubano. Ou seja, o seu caráter de burocrata se reflete em seus textos, não apenas no sentido pejorativo (o culto ao modelo soviético), mas pela sua visão global e estratégica das questões 
midiáticas - no caso, do cinema e da televisão. Em suma, não podemos pensar as mídias em termos de filmes ou de programas, mas na totalidade do seu fenômeno, a saber, a produção, a distribuição, a exibição e a recepção das obras audiovisuais. Por tal motivo, a relevância da televisão se deve, como sublinha García Espinosa, à condensação desses fatores, inclusive sob uma única figura: o diretor de programação. O tom global das ideias de García Espinosa aponta tanto para os aspectos positivos quanto para os negativos (positivos: uma produção mais racionalizada e a descaracterização do artista como um ser isolado e "mágico"; negativos: a consolidação da mediocridade pela difusão massiva de um modelo hegemônico). É a vitória da indústria midiática como "espetáculo". Porém, devemos recordar que a "linguagem audiovisual", por ser algo em formação, se presta tanto para a "comunicação" quanto para o "espetáculo". Graças a essa ambiguidade, o autor chega a uma outra discussão: qual é a relação entre a ficção e a realidade?

Eis um tema, oriundo do Neorrealismo, que subjaz em todo o pensamento garcia-espinosiano. O que singulariza a narrativa audiovisual? Quais são os seus procedimentos técnico-estéticos mais condizentes com a (nossa) realidade (subdesenvolvida)? Em suma, que vínculo existe entre a ficção audiovisual e a realidade? Para tentarmos desvelar essas questões, podemos postular dois aspectos. Um é o cientificismo, tipicamente marxista, que dialetiza a relação ciência-arte. O avanço científico-tecnológico transforma radicalmente as artes, libertando-as de "falsas questões". Implicitamente, nos parece que, para o autor, a arte, cuja origem está relacionada com a religião, era encarada como uma forma de conhecimento do mundo pelas pessoas. Com a consolidação e a expansão da ciência, as atividades científicas legaram à arte uma outra função. A relação lúdica com o mundo é sublinhada pelo autor como uma das características do pensamento infantil. ${ }^{15}$ Mas qual é o papel da atividade 
ano I número I

temáticas

livres

lúdica no pensamento adulto? Esse é o problema com que o autor esbarra, conforme já vimos, ao refletir sobre a herança que o "cinema de espetáculo" delega ao processo revolucionário. Questão sem resposta. O segundo aspecto a ser considerado é que o cinema e a televisão são frutos da revolução técnicocientífica, o que significa que, em sua natureza, possuem uma outra relação com a realidade, diferente das artes tradicionais. Cremos que é possível afirmar que há um realismo presente no pensamento garcia-espinosiano ao reconhecer um vínculo inerente - ontológico, como em André Bazin? - do audiovisual com a realidade. ${ }^{16}$ Todo o problema se deve à originalidade desse fator, que nos conduz a uma ausência de parâmetros para pensarmos tal fenômeno. É assim que, infelizmente, a ideologia pré-industrial parasita a nossa relação com as mídias. Por outro lado, as ciências (no caso, as "humanas") nos auxiliam a nos libertarmos da ideologia esteticista. O ideal é a conciliação da atividade científica com a artística, que culminaria no fim da cisão dessas duas relações do homem com o mundo. Cremos ser redundante afirmar que esse divórcio, para o autor, não existirá no socialismo.

\section{Conclusão}

Em "Por un cine imperfecto", García Espinosa assinala que a própria arte moderna espelha uma contradição inerente à sociedade de classes, sobretudo pelo agravamento da "aberração" que constitui a figura do artista profissional. Lembremos que a criação artística é uma atividade “desinteressada”, ou seja, não possui um fim determinado. No entanto, a arte é absorvida pelas relações de classe. Pelo desenvolvimento dos meios

16. "O cinema e a televisão podem nos mostrar a realidade como se não existissem mediações entre a realidade que oferecem e a própria realidade. No entanto, não podemos deixar de ter em conta que as mediações sempre facilitaram para que ninguém confundisse a realidade com a arte e, na medida em que mais se evidenciaram, maiores foram as possibilidades de que a arte nos ajudasse a perceber a realidade." Transcrito de "Los cuatro medios de comunicación...” (GARCÍA ESPINOSA, 1996: 65). 
técnicos, contudo, é possível a dissolução da sociedade de classes, cabendo ao artista se inserir no processo revolucionário. Desse modo, se alcançaria, em última instância, o fim das separações sociais - entre elas, a existente entre produtores e consumidores de arte. Ao afirmar que o futuro da arte é o do "folclore", García Espinosa, à primeira vista, parece dizer que é necessário dar condições para que a maior parte da população possa exercer as suas inclinações artísticas, promover o acesso das massas aos meios de produção artística. No entanto, em se tratando do cinema e, sobretudo, da televisão, a solução não é tão simples. É por isso que García Espinosa vai, ao longo dos anos 1970, refletir sobre as mídias, como um exercício de esclarecimento de suas ideias postas no célebre artigo de 1969. A própria recusa do senso comum de atribuir à televisão um status artístico manifesta a necessidade de uma revisão do conceito de arte na sociedade industrial.

Como fazer tal revisão? O entusiasmo terceiro-mundista de García Espinosa privilegia um marco referencial: "os que lutam", os povos que se levantam contra o imperialismo. Assim, o cinema militante - o "cine imperfecto" deve ser avaliado (e, nesse ponto, a crítica aos críticos de cinema) por sua contribuição à luta anti-imperialista, o que significa que: 1) o "cine imperfecto" é provisório (com o fim do imperialismo, ele deixará de ter sentido); 2) por conseguinte, um outro cinema, um "cinema popular", irá sucedê-lo; e 3) a ultrapassagem do "cine imperfecto" significa uma outra "cultura", que ainda nem podemos claramente vislumbrar. Na verdade, para García Espinosa, essa prática já está ocorrendo no que ele chama de arte popular. Cabe ao artista, por sua vez, assegurar um canal idôneo para estabelecer um diálogo com o povo, visando à sua proletarização. E, nesse ponto, o leninismo do autor se manifesta da forma mais evidente.

No entanto, se García Espinosa confia no modelo soviético, por sua vez, ao analisar as mídias, ele reconhece que ainda há muito o que fazer. É importante ressaltar que no final de seu extenso texto “Los cuatro medios de comunicación...”, o cubano reconhece um meio idôneo que deve ser preservado: o "movimiento 
ano I número |

temáticas

livres

de aficcionados". A espontaneidade de um cinema amador, fruto da cinefilia, é a manifestação popular no meio cinematográfico. São pessoas que amam o cinema e que produzem os seus filmes graças aos meios técnicos rudimentares que possuem. É significativo que García Espinosa ainda reconheça algum papel aos críticos e aos especialistas (os cineastas profissionais), mas é fundamental preservar os "aficcionados", pois os profissionais são os mais interessados em aprender com a criação espontânea do povo. O que nos salta aos olhos nesse discurso é como a cinefilia é politizada ao ser interpretada como uma manifestação tipicamente popular. ${ }^{17}$ Reconhecemos que há um complexo jogo retórico, típico do leninismo, em dialetizar a vanguarda política com as massas - nesse caso, entre os especialistas (cineastas e críticos) e o povo.

García Espinosa não nega o papel da vanguarda artística, mas o chamado "cinema experimental" não pode ser a única solução para os dilemas do cineasta no processo revolucionário. Concordamos que o amplo conceito de "cine imperfecto" absorve, inclusive, o experimentalismo, mas - eis o fundamental - a linguagem audiovisual deve ser pensada em prol da luta revolucionária, o que significa que não há juízos estéticos a priori para analisar o cinema militante. Portanto, o filme deve ser avaliado por seu objetivo na Revolução, a saber, que tipo de relação deseja criar com o público e, por conseguinte,

17. Esse elogio ao cinema amador vai ao encontro da política cultural adotada pelo governo cubano a partir da segunda metade dos anos 1970, após o período mais duro do regime - o chamado "qüinqüenio gris" (1971-1975). O fomento às atividades artísticas fora das instituições culturais tradicionais - como o ICAIC, no caso do cinema - se insere em um novo contexto do país, de "maior" liberdade e de reestruturação do próprio Estado cubano, com a promulgação da Constituição de 1976, que cria o Ministério da Cultura (Mincult), retirando, por conseguinte, a autonomia de instituições como o ICAIC. Tais medidas provocaram "sacudidelas" no âmbito cultural do país: "Ao suavizar o controle sobre as pequenas instituições, como as casas de cultura, as associações de amadores, os clubes de aficcionados, em detrimento do acirramento da fiscalização dos grandes institutos, o Ministério [da Cultura] talvez pretendesse abarcar todas as manifestações e expressões, inserindo-as formalmente dentro das estruturas do Estado. Entretanto, ao invés de assegurar uma amplitude maior de controle, acabou tendo que enfrentar vários focos dispersos de contestação oriundos de uma espécie de 'reação em cadeia', reação essa que ainda motivou grandes instituições como o ICAIC a brigarem pela recuperação da liberdade perdida (...)." (VILLAÇA, 210: 289). Para maiores informações, ver Villaça (2010: 275-289, 325-336 e 346-373). 
a coerência entre o uso da linguagem audiovisual com o meio no qual o filme é vinculado. Como já vimos, o que mais preocupa García Espinosa é o cinema das salas convencionais, lugar por excelência do comercialismo e do espetáculo. No entanto, o esforço em se pensar uma produção revolucionária para esse espaço tradicional provém do princípio de que o espectador comum já está acostumado a uma concepção de cinema ("cinema de gênero"), e é por essa concepção que o cineasta deve começar a dialogar com ele. Em suma, é fundamental absorver e processar os códigos narrativos e estéticos da produção hegemônica, uma vez que a formação estética do público (e dos próprios realizadores) se deu através dessa produção estrangeira hegemônica (hollywoodiana, ou seja, nos termos do autor, imperialista). No entanto, se o cinema amador é visto como uma salvaguarda para a elitização da produção audiovisual, apontando, segundo García Espinosa, para um novo conceito de obra de arte condizente com a sociedade industrial, a dificuldade de lidar com as estruturas estético-narrativas herdadas da sociedade burguesa é reconhecida, mas não totalmente resolvida. Como se faz para superar essa herança, em direção a uma “arte industrial”, é algo sem respostas peremptórias. Não podemos deixar de frisar que, embora visto com bons olhos, o "cinema amador" ainda está sob a sombra dessa herança.

Portanto, voltamos a interrogar: afinal, o que é o "cine imperfecto"? É uma atividade que visa, paradoxalmente, terminar com a figura do cineasta, i.e., com um grupo de especialistas que detêm o conhecimento e a posse dos meios de produção audiovisual. O fim último do processo revolucionário é garantir a todas as pessoas a criação artística. Mas o que é a arte na sociedade industrial? Para responder a essa questão, é necessário nos voltarmos para as mídias, mais especificamente o cinema e a televisão. Urge pensar um novo conceito de arte que seja compatível com a sociedade industrial. As mídias audiovisuais condensam essa inter rogação pelo fato de serem criações oriundas da revolução científico-técnica, que modificou radicalmente a relação do ser humano com o 
ano I número I

temáticas

livres

mundo. Mais do que isso, elas tornaram possível a transformação das relações dos humanos entre si, o que permitirá, segundo o marxismo, a dissolução da sociedade de classes. O imperialismo, porém, nos legou uma forma de pensar o audiovisual (não apenas os seus aspectos narrativos, mas toda uma estrutura global: produção, difusão e recepção). A burguesia, sobretudo a estadunidense, escamoteou a sua ideologia de classe ao criar o populismo, ou seja, uma falsa participação das massas nas mídias. Cabe ao revolucionário separar os aspectos negativos dos positivos das mídias e buscar criar um cinema popular (melhor dito, uma narrativa fílmica/televisiva popular), tanto em termos de construção narrativa (principalmente, já que é o problema mais espinhoso herdado do imperialismo) quanto em termos de estrutura global, ou seja, a posse coletiva dos meios de produção audiovisual, que significa uma autêntica inter-relação entre quem cria o produto audiovisual (fílmico ou televisivo) e quem o recebe . Somente dessa forma é lícito chamar tais mídias de "meios de comunicação de massa". Em suma, uma relação autêntica entre o que está nas mídias e o que está na realidade. Se o autor louva muitos fatores das mídias, isso se deve à sua fé na conscientização e organização política das massas. Ou seja, é algo que está na realidade social. Por outro lado, se as mídias "falseiam" a realidade, isso se deve à nefasta ação da ideologia burguesa (o populismo). Ou seja, é algo que também está na realidade social: uma superestrutura ideológica defasada em relação ao avanço científico-técnico. Dito de outro modo, García Espinosa segue ao pé da letra os fundamentos do marxismo-leninismo: há um descompasso entre as forças produtivas e as relações de produção e, por conseguinte, a revolução social deve promover a coletivização dos meios de produção. Portanto, a face negativa das mídias se deve ao resquício burguês, ou seja, a uma ideologia esteticista que obstina pensar/julgar/tratar as mídias conforme a concepção classista ("pré-industrial") de arte. Isso é válido para todos: os especialistas (os artistas), os críticos e o público geral (as massas). Portanto, a falsa relação entre a mídia e a realidade social é fruto de uma consciência típica de uma sociedade a cuja totalidade uma determinada classe impõe sua visão de mundo como a 
verdadeira, visando à manutenção das relações que compõem essa sociedade. Em termos marxistas: ideologia.

Para finalizar, reiteramos que o objetivo do presente ensaio foi reconfigurar o célebre artigo de 1969 de García Espinosa, assinalando os seus principais tópicos, relacionando-o com o seu desenvolvimento teórico posterior, conforme as preocupações entranhadas no contexto cultural cubano dos anos 1970. Por outro lado, não podemos deixar de evidenciar que o célebre texto ainda nos diz muito, sobretudo com a atual expansão da produção audiovisual, graças à tecnologia digital. No entanto, se nos dias de hoje ocorre um boom na produção audiovisual, nunca foram feitos tantos esforços para controlar a difusão. O mesmo podemos afirmar em relação à crítica, quando blogues e sites se consolidam, cada vez mais, como espaços de reflexão e erudição perdidos nos grandes meios impressos da mídia convencional. Frisamos também que, atualmente, também se comenta muito sobre as mobilizações políticas e a sua relação com as chamadas "redes sociais", conforme demonstram os recentes e conturbados eventos pelo mundo afora, como a Primavera Árabe, o Inverno Chileno, os protestos na Espanha e na Grécia, a revolta nos subúrbios londrinos, o acampamento em Wall Street, o movimento dos indignados etc., que prolongam, de outro modo, os protestos antiglobalização dos anos 1990. No entanto, por outro lado, já não possuímos o otimismo dos áureos tempos do terceiro-mundismo, segundo um paradigma "salvacionista" de Revolução. 


\section{Referências bibliográficas}

ano 1 número 1

temáticas

livres

AVELLAR, José Carlos. A ponte clandestina: Birri, Glauber, Solanas, Getino, García Espinosa, Sanjinés, Alea - teorias de cinema na América Latina. Rio de Janeiro: Ed. 34; São Paulo: Edusp, 1995. 319 p.

CÉSAIRE, Aimé. Discours sur le colonialisme. 6ª ed. Paris: Présence Africaine, 1973. $58 \mathrm{p.}$

FANON, Frantz. Les damnés de la terre. Paris: Gallimard, 1991. 384 p.

GARCÍA ESPINOSA, Julio. La doble moral del cine. Madri: EICTV; Ollero \& Ramos, 1996. 158 p.

. Por un cine imperfecto. Caracas: Fondo Editorial Salvador de la Plaza, 1970.

69 p.

GETINO, Octavio; VELLEGGIA, Susana. El cine de "las historias de la revolución": aproximación a las teorías y prácticas del cine de "intervención política" en América Latina (1967-1977). Buenos Aires: Altamira, 2002. 189 p.

VILLAÇA, Mariana. Cinema cubano: revolução e política cultural. São Paulo: Alameda, 2010. 440 p. 